\title{
Threshold Effects of Environmental Regulation on Total Factor Energy Efficiency in China
}

\author{
Ling Yun Huang and Hui Qiang Xie* \\ ${ }^{I}$ School of Economics and Business Administration, Chongqing University, Chongqing 400044, China \\ ${ }^{2}$ School of Economics and Business Administration, Chongqing University, Chongqing 400044, China
}

\begin{abstract}
This paper examines the threshold effects of environmental regulation on China's total factor energy efficiency (TFEE) using technological innovation (as measured by patents) as a threshold variable. Using the Slacksbased measure-undesirable (SBM-undesirable) output model, we first estimate TFEEs in 30 Chinese provinces from 2000 to 2011 under the constraints of energy conservation and emissions reduction. We then analyze the impact of environmental regulation on TFEE based on the panel threshold regression model. The results show that the average TFEE in China from 2000 to 2011 is 0.503 , indicating that this measure can be significantly improved. However, environmental regulation has threshold effects on TFEE. Stringent environmental regulation can only improve TFEEs in provinces with technological innovation levels between the first and second threshold values. When technological innovation levels are below the first or above the second threshold value, tighter environmental regulation would lower TFEE. The results suggest that environmental regulation does not always enhance TFEE and that the positive effect of environmental regulation on TFEE must fall within a range of threshold values. In addition, improving the technological innovation level and adjusting the industrial structure have positive effects on TFEE, while the irrational energy consumption structure has a negative effect on TFEE.
\end{abstract}

Keywords: Environmental regulation, technological innovation, threshold effects, total factor energy efficiency.

\section{INTRODUCTION}

As the world's largest energy consumer in 2012, China's primary energy consumption accounted for $21.9 \%$ of total global energy consumption. This rate may increase to $26.6 \%$ in 2035 according to British Petroleum's "Energy Outlook 2035". In the same year, Yale University and Columbia University launched the annual global Environmental Performance Index (EPI), which includes 178 countries and regions, and China ranked 118th. The increasing energy consumption and worsening ecological environment indicate that China's traditional pattern of economic development has seriously affected and restricted the country's economic and social sustainability. Ensuring sustainable economic growth under the premise of energy conservation and pollution abatement has become a major issue in China. Recently, the Chinese government has gradually increased the intensity of environmental regulation to encourage companies to explore technological innovations and improve TFEE through energy conservation and emissions reduction. However, how can TFEE be measured effectively? Can intensifying environmenttal regulation improve TFEE? Is the impact of environmental regulation on TFEE linear?

This study aims to find answers to these questions. We use the SBM-undesirable model to estimate TFEEs in China's 30 provinces from 2000 to 2011 using the chemical oxygen demand (COD) of wastewater, sulfur dioxide

*Address correspondence to this author at the No. 174 Shazhengjie, Shapingba, Chongqing, China. Postcard: 400044; Tel: 18875209067 ; E-mail:541381689@qq.com emissions and carbon dioxide emissions from exhaust gases as unexpected output. In addition, we propose a panel threshold model to analyze the impacts of environmental regulation on TFEE using technological innovation as the threshold variable. These analyses were conducted in the context of energy conservation and emissions reduction. Using careful empirical examinations, we hope to yield useful suggestions for governmental regulation and policy making, as well as for future research studies concerning the relationship between environmental regulation and TFEE.

The next section provides a brief literature review of the relationship between environmental regulation and energy efficiency. Then, we describe and evaluate the econometric model and data resources. Next, the empirical results and relative tests are presented and explained. Finally, we conclude with some policy implications and future research challenges and opportunities.

\section{LITERATURE REVIEW}

Early economists held that environmental regulation would increase the cost of production, thus reducing production efficiency. For instance, Gollop and Roberts [1] (1983) analyzed the $\mathrm{SO}_{2}$ emission controls in the United States from 1973 to 1979 and found that environmental regulation decreased the industrial production efficiency. Gray (1987) [2] estimated the effect of environmental regulation on the manufacturing productivity in the United States and found that regulation reduced the industrial productivity by $30 \%$ from $1958-1978$. However, some recent studies have shown effects that are more positive. Now 
known as "Porter Hypothesis", Porter (1995) [3] argued that a well-designed environmental regulation can trigger technological innovation that may offset the cost of regulatory compliance due to cost reduction, thereby improving the industry productivity. Berman and Bui (2001) [4] and Sabuj (2010) [5] also reported that environmental regulation can improve industrial energy efficiency. $\mathrm{Bi}$ (2013) [6] analyzed the relationship between fossil fuel consumption and the environmental regulation of China's thermal power generation, finding that decreasing the discharge of major pollutants can significantly improve the energy performance and efficiency.

From the above studies, we conclude that no consensus exists as to whether environmental regulation can promote energy efficiency. This lack of consensus is due to multiple reasons. First, the methods for measuring energy efficiency vary. Some scholars use single factors to measure energy efficiency, while others use total factors. Furthermore, some measurement methods are based on radial or oriented functions that do not consider slack problems associated with inputs and outputs. Therefore, the energy efficiency is biased. Additionally, the effect of environmental regulation on TFEE may be nonlinear. Whether environmental regulation can improve TFEE may be largely determined by the level of technological innovation. Namely, the effective size and direction of the environmental regulation on TFEE may be different due to different technological innovation levels.

\section{MODELS AND DATA}

\subsection{SBM-Undesirable Model}

The SBM model was originally proposed by Tone (2001) [7]. The model effectively solved the slack problems associated with inputs and outputs. However, the traditional SBM model neglected the environmental impacts of undesirable outputs when assessing TFEE. Tone (2004) [8] proposed the SBM-undesirable model, adding undesirable outputs into the traditional SBM model. This paper adopts Tone's SBM-undesirable model to evaluate China's regional TFEE under the restrictions of energy conservation and emissions reduction. Assuming that there are $n$ decision making units (DMU) at point $t$, each unit has $m$ types of input $X, s$ types of good (desirable) output $Y$ and $t$ types of bad (undesirable) output $B$, the production possibility set(P) is defined as follows:

$\mathrm{P}=\{(X, Y, B) \mid x \geq X \lambda, y \geq Y \lambda, b \geq B \lambda, \lambda \geq 0\}$

where $\lambda \in \mathrm{R}^{\mathrm{n}}$ is the intensity vector. Note that the above definition corresponds to the constant returns to scale technology. In accordance with the above-mentioned production technology, Cooper et al. (2007) [9] proposed the CRS-SBM model with undesirable outputs to calculate the technical efficiency of a production system. The CRS-SBM model with undesirable outputs for the $i^{\text {th }}$ decision-making unit at phase $t$ is as follows:

$$
\min \rho=\frac{1-\frac{1}{m} \sum_{j=1}^{m} \frac{s_{j}^{-}}{x_{j 0}}}{1+\frac{1}{s+t}\left(\sum_{r=1}^{s} \frac{s_{r}^{+}}{y_{r 0}}+\sum_{p=1}^{t} \frac{s_{p}^{+}}{b_{p 0}}\right)}
$$

$$
\begin{gathered}
\text { s.t. } \sum_{i=1}^{n} \lambda_{i} x_{j i}+s_{j}^{-}=X_{0}, j=1,2 \ldots m \\
\sum_{i=1}^{n} \lambda_{i} y_{r i}-s_{r}^{+}=Y_{0}, r=1,2 \ldots s \\
\sum_{i=1}^{n} \lambda_{i} b_{p i}+s_{p}^{+}=B_{0}, p=1,2 \ldots t
\end{gathered}
$$

$s_{j}^{-} \geq 0, s_{r}^{+} \geq 0, s_{p}^{+} \geq 0, \lambda_{i} \geq 0$.

where $s_{i}^{-}, S_{r}^{+}$and $S_{p}^{+}$represent input redundancy, expected output redundancy and unexpected output redundancy, respectively. $\lambda_{i}$ is a nonnegative multiplier vector for technology construction. In this study, the good output contains regional GDP, while $\mathrm{CO}_{2}$ and $\mathrm{COD}$ are the bad outputs. The input vectors contain capital, labor and energy consumption. $\rho$ is defined as TFEE. If $\rho=1$, which indicates that all the slack variables are 0 , the TFEE of the province is efficient in the presence of undesirable outputs.

\subsection{Panel Threshold Model Of Environmental Regulation on TFEE}

The Porter Hypothesis posits that a well-designed environmental regulation can spur technological innovation that may reduce production cost, and thus enhance industrybased productivity. Therefore, the ability of environmental regulation to promote productivity depends on the effects of technological innovation and the costs of environmental regulation. When a government increases the intensity of environmental regulation, firms generally decrease their pollution levels to the new standard in one of two ways. They may increase inputs to pollution abatement, which would produce a cost of regulation and increase the production cost, thereby reducing TFEE under the restrictions of energy conservation and emissions reduction. However, firms may increase their energy efficiencies by adopting technological innovations to optimize resources allocation, leading to a "win-win" situation that reduces pollution and to improve the level of output and TFEE under the restrictions of energy conservation and emissions reduction. This is the so-called innovation offset effect. In regions with low levels of technological innovation, the cost is relatively low if firms adopt the first environmental regulation approach, as opposed to choosing technological innovation. Therefore, firms tend to adopt the first approach to meet the emissions reduction standard. In this manner, more intense environmental regulation would reduce TFEE under the restrictions of energy conservation and emissions reduction. However, in areas with high levels of technological innovation, the cost is relatively high if firms adopt the first approach, while the cost of technological innovation is lower. Thus, firms prefer the second approach to meet the standard. In this manner, the more intense environmental regulation will increase TFEE. As a result, the effect of environmental regulation on TFEE has a threshold. This paper uses the panel threshold regression mode proposed by Hansen (1999) [9] to empirically analyze the threshold effect of environmental regulation on TFEE. The Panel threshold model is expressed as follows: 


$$
\begin{aligned}
\mathrm{EE}_{\mathrm{it}}= & \beta_{0}+\beta_{11} E R_{i t} * I\left(I N N I O_{i t} \leq \gamma_{1}\right)+ \\
& \beta_{12} E R_{i t} * I\left(\gamma_{1} \leq I N N I O_{i t} \leq \gamma_{2}\right) \\
& +\ldots \beta_{1 n} E R_{i t} * I\left(\gamma_{n} \leq I N N I O_{i t}\right)+\beta_{2} E R_{i t-1} \\
& +\beta_{3} I N N O_{i t}+\beta_{4} I S_{i t}+\beta_{5} E C S_{i t}+\varepsilon_{i t}
\end{aligned}
$$

where $i$ and $t$ denote the region and year, respectively; $E E_{i t}$ represents TFEE under the restrictions of energy conservation and emissions reduction; INNO ${ }_{i t}$ represents technological innovation; $E R_{i t-1}$ denotes the first-lagged period of environmental regulation; $I(*)$ is the indicator function; $I N N O_{i t}$ is a threshold variable; $\gamma_{1} \gamma_{2} \cdots \gamma_{n}$ is the threshold value; and $\beta_{11} \beta_{12} \cdots \beta_{1 n}$ is the effect of the intense environmental regulation on TFEE under the restrictions of energy conservation and emissions reduction within different levels of innovation. Relevant test methods refer to the test methods proposed by Hansen (1999) [10].

\subsection{Variables and Data Sources}

This paper uses panel data from China's 30 provinces from 2000 to 2011 as samples, excluding Hong Kong, Macao, Taiwan and Tibet, for which corresponding statistics are not available. The input indicators are as follows: labor, taking the current employment as the labor input, i.e., the mean employment of the current year and previous year; capital stock, using gross fixed capital formation as capital stock index to calculate the capital stocks of 30 provinces in China from 2000 to 2011 with a depreciation rate of $10.96 \%$; and energy consumption, setting each province's total energy consumption as the energy consumption index. The output indicators are as follows: the expected output, which is the real GDP based on the period (2000); and the unexpected output, which includes the chemical oxygen demand (COD) of wastewater, sulfur dioxide emissions and carbon dioxide emissions from exhaust gases. Because there are no official $\mathrm{CO}_{2}$ emissions statistics, we calculate the $\mathrm{CO}_{2}$ emissions using the IPCC methodology (2006). The formulation is

$$
E C=\sum_{i=1}^{7} E_{i} \times E F_{i},
$$

where $E C$ denotes the estimated value of total $\mathrm{CO}_{2}$ emissions from all types of energy consumption; $i$ represents the energy consumption categories, which include coal, coke, gasoline, kerosene, diesel oil, fuel oil and natural gas; and $E_{i}$ denotes the total energy consumption of the $\mathrm{i}^{\text {th }}$ energy. $E F_{i}$ is the carbon dioxide emission coefficient of the $\mathrm{i}^{\text {th }}$ energy type, and coal, coke, gasoline, kerosene, diesel oil, fuel oil and natural gas carbon dioxide emission coefficients are 1.647 tons $\mathrm{CO}_{2} /$ ton, 2.848 tons $\mathrm{CO}_{2} /$ ton, 3.045 tons $\mathrm{CO}_{2} /$ ton, 3.174 tons $\mathrm{CO}_{2} /$ ton, 3.150 tons $\mathrm{CO}_{2} /$ ton, 3.064 tons $\mathrm{CO}_{2} /$ tons and 21.670 tons $\mathrm{CO}_{2} /$ cubic meter.

The control factors affecting TFEE are as follows: (1) environmental regulation $E R_{i t}$, is based on the ratio of the industrial pollution control investment to the industrial output. The higher the $E R_{i t}$ value, the greater the intensity of the environmental regulation. TFEE exhibits a lag effect with the impact of environmental regulation. The first-lagged period of environmental regulation is taken as an explanatory variable; (2) technological innovation $I N N O_{i t}$ is based on the number of patents granted, providing a proxy indicator of the technological innovation output; (3) industrial structure $I S_{i t}$ is the ratio of the added value of the second industry to GDP based on the Industrial Structure index; (4) energy consumption structure $E C S_{i t}$ is the rate of coal consumption compared to the total energy consumption, providing an indicator of the energy consumption structure.

The data resources used in this study include the China statistical yearbook, China environment yearbook, China statistical yearbook on science and technology, China's environmental statistics yearbook and all provincial statistical yearbooks.

\section{TESTS AND RESULTS}

\subsection{TFEE Under the Restrictions of Energy Conservation and Emissions Reduction}

According to the SBM-undesirable model, we calculate TFEE under the restrictions of energy conservation and emissions reduction using the data from China's 30 provinces from 2000 to 2011 .

Table 1. Mean values of the provincial TFEEs from 2000 to 2011.

\begin{tabular}{|c|c|c|c|}
\hline Provinces & $\begin{array}{c}\text { Energy } \\
\text { efficiency }\end{array}$ & Provinces & $\begin{array}{c}\text { Energy } \\
\text { efficiency }\end{array}$ \\
\hline \hline Yunnan & 0.966 & Shandong & 0.450 \\
\hline Fujian & 0.927 & Guangxi & 0.447 \\
\hline Liaoning & 0.800 & Hubei & 0.431 \\
\hline Guangdong & 0.777 & Jilin & 0.421 \\
\hline Hainan & 0.716 & Henan & 0.367 \\
\hline Tianjin & 0.705 & Hebei & 0.364 \\
\hline Zhejiang & 0.696 & Shanxi & 0.341 \\
\hline Anhui & 0.687 & Shaanxi & 0.337 \\
\hline Beijing & 0.658 & Jiangxi & 0.327 \\
\hline Shanghai & 0.593 & Xinjiang & 0.315 \\
\hline Jiangsu & 0.558 & Inner Mongolia & 0.290 \\
\hline Sichuan & 0.505 & Qinghai & 0.257 \\
\hline Heilongjiang & 0.502 & Ningxia & 0.256 \\
\hline Hunan & 0.488 & Guizhou & 0.240 \\
\hline Chongqing & 0.469 & Gansu & 0.207 \\
\hline
\end{tabular}

From Table 1, we conclude that the mean Chinese TFEE from 2000 to 2011 is 0.503 . The highest energy efficiency score exhibited in Yunnan province, reaching 0.966, while the lowest score is exhibited in Gansu province at only 0.207 . According to the level of energy efficiency, we divide the areas into three groups: areas with high energy efficiency (Yunnan, Fujian, Liaoning, Guangdong, Tianjin, Hainan, Zhejiang, Anhui, Beijing and Shanghai); areas with moderate energy efficiency (Jiangsu, Sichuan, Heilongjiang, Hunan, Chongqing, Shandong, Guangxi, Hubei, Jilin and Hebei); areas with low energy efficiency (Henan, Jiangxi, 
Shanxi, Shaanxi, Xinjiang, Inner Mongolia, Qinghai, Ningxia, Guizhou and Gansu).

\subsection{Empirical Analysis of the Impact of Environmental Regulation on TFEE}

According to the empirical analysis and tests using the model (3), we first must determine the number of thresholds. The results show that the threshold of the technological innovation variable has two threshold values, as shown in Table 2.

Table 2. Threshold effect bootstrap test of the threshold the technological innovation variable.

\begin{tabular}{|c|c|c|c|c|c|}
\hline $\begin{array}{c}\text { Threshold } \\
\text { number }\end{array}$ & F-value & $\begin{array}{c}\mathbf{P}- \\
\text { value }\end{array}$ & $\mathbf{1 \%}$ & $\mathbf{5 \%}$ & $\mathbf{1 0 \%}$ \\
\hline \hline 1 & $21.764^{* *}$ & 0.015 & 24.603 & 14.983 & 10.955 \\
\hline 2 & $34.395^{* * *}$ & 0.000 & 16.138 & 6.784 & 1.777 \\
\hline 3 & 6.285 & 0.207 & 28.214 & 17.061 & 10.965 \\
\hline
\end{tabular}

Note: $* * * * *$ and $*$, significant at $1 \%, 5 \%$ and $10 \%$, respectively. The numbers in brackets are the LM test statistics determined by the "sampling method" (the bootstrap) repeated 1000 times.

Table 3. Threshold estimation and confidence interval.

\begin{tabular}{|c|c|c|c|}
\hline $\begin{array}{c}\text { Threshold } \\
\text { variable }\end{array}$ & $\begin{array}{c}\text { Threshold } \\
\text { number }\end{array}$ & $\begin{array}{c}\text { Threshold } \\
\text { estimation }\end{array}$ & $\begin{array}{c}\text { 95\% confidence } \\
\text { interval }\end{array}$ \\
\hline \hline $\begin{array}{c}\text { Technological } \\
\text { innovation }\end{array}$ & Threshold 1 & 1.066 & {$[0.662,1.440]$} \\
\hline & Threshold 2 & 12.388 & {$[11.934,13.838]$} \\
\hline
\end{tabular}

Table 4. Threshold value and its distribution.

\begin{tabular}{|c|c|}
\hline $\begin{array}{c}\text { Threshold } \\
\text { value interval }\end{array}$ & Provinces (2011) \\
\hline \hline & $\begin{array}{c}\text { Qinghai, Ningxia, Guizhou, Hainan, Inner } \\
\text { Mongolia, Gansu, Xinjiang, Yunnan, Guangxi, } \\
\text { Jiangxi, Jilin, Shanxi }\end{array}$ \\
\hline $\begin{array}{c}1.066<\mathrm{INNO}<1.066 \\
2.388\end{array}$ & $\begin{array}{c}\text { Hebei, Shanxi, Heilongjiang, Tianjin, Chongqing, } \\
\text { Hunan, Hubei, Liaoning, Anhui, Henan, Fujian, } \\
\text { Sichuan, Beijing, Shanghai, Shandong }\end{array}$ \\
\hline $\mathrm{INNO}>12.388$ & Guangdong, Zhejiang, Jiangsu \\
\hline
\end{tabular}

From Table 3 and Table 4, we conclude that the threshold estimations of technological innovation are 1.066 and 12.388. Twelve provinces' technological innovation levels are below the first threshold value in 2011, including Qinghai, Ningxia, Guizhou, Hainan, Inner Mongolia, Gansu, Xinjiang, Yunnan, Guangxi, Jiangxi, Jilin and Shanxi. Fifteen provinces' technological innovation levels are between the first and second threshold, including Hebei, Shanxi, Heilongjiang, Tianjin, Chongqing, Hunan, Hubei, Liaoning, Anhui, Henan, Fujian, Sichuan, Beijing, Shanghai and Shandong. Three provinces' technological innovation levels are above the second threshold, including Guangdong, Zhejiang and Jiangsu.
Table 5. Panel threshold model regression estimation.

\begin{tabular}{|c|c|c|}
\hline Variable & Coefficient & P value \\
\hline \hline INNO & $0.047^{* * *}$ & 0.000 \\
\hline IS & $0.005^{* * *}$ & 0.000 \\
\hline ECS & $-0.096^{* * *}$ & 0.001 \\
\hline ER $\mathrm{t-1}$ & $-0.049^{* * *}$ & 0.003 \\
\hline ER_1 (INNO<1.066) & $-0.059^{* * *}$ & 0.001 \\
\hline ER_2(1.066<INNO<12.388) & $0.120^{* *}$ & 0.016 \\
\hline ER_3 $(12.388>\mathrm{INNO})$ & $-2.939^{* * *}$ & 0.000 \\
\hline _cons & $0.347^{* * *}$ & 0.000 \\
\hline
\end{tabular}

Note: $* * *, * *$ and $*$ represents significance at $1 \%, 5 \%$ and $10 \%$, respectively.

Based on the regression results in Table $\mathbf{5}$, if the technological innovation level is below the first threshold value, the significant effect of environmental regulation on energy efficiency is negative, and the estimated coefficient is -0.059. Thus, more intense environmental regulation would reduce TFEE. For the provinces with technological innovation levels above the first threshold value, the significant effect of environmental regulation on energy efficiency is positive, and the estimated coefficient is 0.120 . In 2011, the technological innovation level of most developed eastern and some central provinces fell between the first and second threshold values. More stringent but properly designed environmental regulations can improve TFEEs in these regions. For the 3 provinces whose technological innovation levels are above the second threshold, the effect of environmental regulation on TFEE is negative. Thus, decreasing environmental regulation in these areas can improve their TFEE.

\section{CONCLUSION}

This paper estimates China's provincial TFEEs under the restrictions of energy conservation and emissions reduction using data from 30 provinces from 2000 to 2011 . We then discuss the threshold effects of environmental regulation on TFEE based on the empirical data. The results show that the average value of China's TFEE from 2000 to 2011 is 0.503 . The relationship between environmental regulation and TFEE is nonlinear, which is determined by the technological innovation level. When the region's technological innovation level is below the first or above the second threshold value, more intense environmental regulation reduces the region's TFEEs. When the level of technological innovation is between the first and second thresholds, stringent environmental regulation can improve the region's TFEEs. Improving the technological innovation level and adjusting the industrial structure can enhance TFEEs, while the irrational energy consumption structure hinders TFEEs.

These results may have important implications for Chinese environmental policies. First, China's average TFEE under the restrictions of energy conservation and emissions reduction can be significantly improved. Second, understanding how different levels of technological innovation and environmental regulation influence TFEE can 
help policy makers formulate the most appropriate level of environmental regulation based on their regional innovation level. The findings of this study suggest that environmental policy makers should adopt different environmental regulatory policies based on the level of innovation. In the Midwestern provinces of China with low levels of technological innovation, corresponding to provinces with fewer than 10660 patents granted, policy-makers should focus on developing technological innovation through accelerating independent innovation and importing advanced technologies from eastern China and abroad. In central and eastern provinces with technological innovation levels between the first and second threshold values, policy-makers should focus on adopting stricter environmental regulation. In the 3 provinces (Guangdong, Zhejiang, Jiangsu) whose technological innovation levels are above the second threshold value, policy-makers should decrease environmental regulation appropriately. In addition, simultaneously optimizing and upgrading the industrial structure, and decreasing the proportion of coal in the total energy consumption can also improve TFEE.

Ideally, firm and global level data sets could be used to examine the threshold effects of environmental regulation on TFEE in future research. In addition, the impacts of various environmental regulation strategies on TFEE should be evaluated in the future.

\section{CONFLICT OF INTEREST}

The authors confirm that this article content has no conflict of interest.

\section{ACKNOWLEDGEMENTS}

The author would like to thank the anonymous referees and the editor for useful comments. In addition, this research was supported by the Social Science Foundation of China [grant number 14BGJ042].

\section{REFERENCES}

[1] Gollop, F.M.; Robert, M.J. Environmental regulations and productivity growth: The case of fossil fueled electric power generation. J. Pol. Eco., 1983, 91, 654-665.

[2] Gray, W.B. The cost of regulation: OSHA, EPA and the productivity slowdown. Am. Eco. Rev., 1987, 77(5), 998-1006.

[3] Porter, M.E.; van der Linde, C. Toward a new conception of the environment competitiveness relationship. J Eco. Perspect., 1995, 9(4), 97-118.

[4] Berman, E.; Bui, L.T.M. Environmental regulation and productivity: Evidence from oil refineries. Rev. Eco. Stat., 2001, $88,498-510$

[5] Sabuj, K.M. Do undesirable output and environmental regulation matter in energy efficiency analysis? evidence from indian cement industry. Energy Policy, 2010, 38(10), 6076-6083.

[6] Bi,G.-B. Does environmental regulation affect energy efficiency in China's thermal power generation? Empirical evidence from a slacks-based DEA model. Energy Policy, 2013, 66, 537-546.

[7] Tone, K. A slacks-based measure of efficiency in data envelopment analysis. Europ. J. Operat. Res, 2001, 130(3), 498509.

[8] Tone, K. Dealing with undesirable outputs in DEA: A slacks-based measure (SBM) approach. Operat. Res. Soci. Jpn., 2004, 1, 44-45.

[9] Cooper, W.W.; Seiford, L.M.; Tone, K. Data Envelopment Analysis: A Comprehensive Text with Models, Applications, References and DEA-solver Software. 2007.

[10] Hansen, B.E. Threshold effects in non-dynamic panels: Estimation,testing and inference. J. Economet., 1999, 93, 345-368. 